\title{
A natureza-morta: uma reflexão poética e fotográfica
}

Maria Adélia Menegazzo, Programa de Pós-graduação em Estudos de Linguagens, Centro de Ciências Humanas e Sociais, Universidade Federal de Mato Grosso do Sul, Campo Grande, MS; E-mail: <ma.menegazzo@uol.com>.

\section{Resumo}

Nascida como um gênero da pintura holandesa do século XVI, a natureza-morta atendia tanto a um gosto meramente decorativo, quanto à necessidade de reflexões profundas sobre a efemeridade da presença humana no mundo. Enquanto vanitas, tinha como função lembrar que os prazeres e as aparências são passageiras; enquanto memento mori, induzia à reflexão sobre a vida e a morte, atingindo, em ambas, as formas e o caráter alegórico. Desde os primórdios da fotografia, o modelo é a pintura, e o tema da natureza-morta aparece tanto em clássicos como Talbot e Bayard, quanto nos modernos Rodtchenko e Cartier-Bresson. Nosso trabalho pretende investigar as configurações que o tema encontra na poesia contemporânea de Ana Martins Marques, bem como em fotografias de Robert Frank e Francesca Woodmann e em vídeos de Sam Taylor Wood, enfatizando seu caráter indicial, alegórico e narrativo.

Palavras-chave: fotografia, poesia, vídeo, natureza-morta, alegoria, narrativa

Uma das grandes inquietações da arte contemporânea reside na ausência de limites precisos para sua identificação em relação às coisas banais do cotidiano. $\mathrm{Na}$ medida da transformação dos temas comuns em universais humanos é que podemos justificar sua presença como objeto de arte, seja uma instalação, um filme ou um romance. Neste trabalho, toma-se como ponto de partida a ideia de que na experiência estética do cotidiano as artes traçam o seu caminho e busca-se na análise de naturezas-mortas compreender o modo como essa experiência é percebida, as reflexões que pode suscitar e como é configurada. 
O regime estético das artes é, antes de tudo, a ruína do sistema da representação, isto é, de um sistema em que a dignidade dos temas comandava a hierarquia dos gêneros da representação (tragédia para os nobres, comédia para a plebe; pintura de história contra pintura de gênero etc).

Nesta medida, é possível para o autor afirmar que "o banal torna-se belo como rastro do verdadeiro" (Rancière, 2005: 50). O banal, o ordinário são expressões do cotidiano evidenciadas pelas naturezas-mortas.

$\mathrm{Na}$ pintura, a natureza-morta é um gênero objetivamente definido. O termo stilleven foi utilizado pela primeira vez em Flandres, por volta de 1650, como referência aos quadros que apresentassem frutas, flores e peixes ou restos de refeições; foi adotado pelos alemães como stilleben e pelos ingleses, stilllife, que se traduz por vida silenciosa ou vida imóvel. Na Espanha, a expressão para falar das naturezas-mortas é bodegón, na França, nature morte, da qual deriva a expressão em língua portuguesa. Nascida, então, como um gênero da pintura holandesa do século $\mathrm{XVI}$, a natureza-morta atendia tanto a um gosto meramente decorativo, quanto à necessidade de reflexões profundas sobre a efemeridade da presença humana no mundo. Enquanto vanitas (vaidade) tinha como função lembrar que os prazeres e as aparências são passageiros; enquanto memento mori ("Lembra-te que vais morrer!"), induzia à reflexão sobre a vida e a morte, atingindo, em ambas, as formas e o caráter alegórico.

Em A origem do drama barroco alemão, Benjamin (1984: 184) chama a atenção para o fato de que a alegoria foi vista durante muito tempo apenas como "uma relação convencional entre uma imagem ilustrativa e sua significação", mas a partir do período Barroco, torna-se uma expressão, como a linguagem e a escrita. Na diferença entre o símbolo e a alegoria, há o que o autor de Passagens denomina "a decisiva categoria do tempo":

Nisso consiste o cerne da visão alegórica: a exposição barroca, mundana, da história como história mundial do sofrimento, significativa apenas nos episódios do declínio. Quanto maior for a significação, tanto maior a 
sujeição à morte, porque é a morte que grava mais profundamente a tortuosa linha de demarcação entre a physis e a significação. Mas se a natureza desde sempre esteve sujeita à morte, desde sempre ela foi alegórica. (Benjamin, 1984: 188)

Assim, Benjamin conclui que a alegoria nasce de uma curiosa combinação de natureza e história, expressa decisivamente pelo drama barroco alemão, quando se funde ao cenário como ruína. "Sob essa forma, a história não constitui um processo de vida eterna, mas de inevitável declínio. As alegorias são no reino dos pensamentos o que são as ruínas no reino das coisas. Daí o culto barroco das ruínas" (Benjamin, 1984: 200). O símbolo está posto como convenção, aceito como estereótipo, enquanto a alegoria processa uma historicização do tema na medida de sua atualização.

Alguns estudos sobre o Barroco como os de Wolfflin (1970) e de Hauser (1980) atentam para o fato de que as cenas captam um instante da ação, portanto, podem também ser vistas como um fragmento. No caso das naturezas-mortas, podemos refletir na mesma medida, considerando-as como um fragmento da vida cotidiana. Assim sendo, a beleza que dura resulta do saber, é um detalhe de suas referências alegóricas. O historiador da arte H. W. Janson (1977: 515) também afirma que a natureza-morta tinge-se do sentimento melancólico do efêmero de todos os prazeres terrenos.

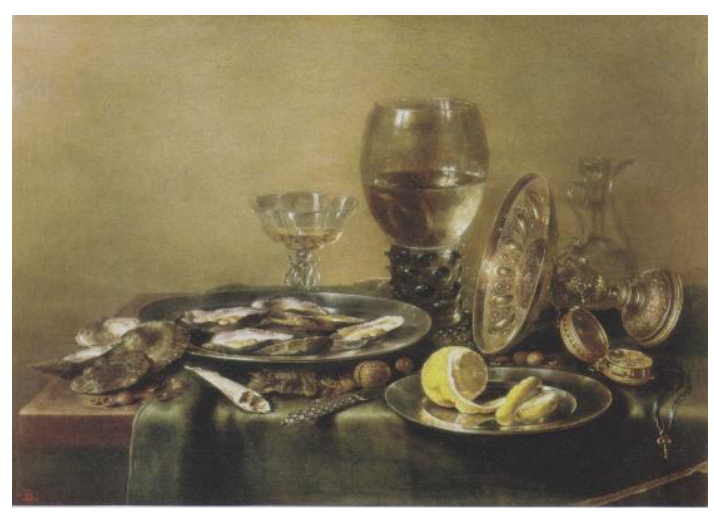

Figura 1: Willem Claesz Heda - Still-Life. 1632 - Oil on oak panel, $59 x$ $76 \mathrm{~cm}$. Private collection. Acesso em 12 de janeiro de 2015, from http://www.wga.hu/index1.html. 
Ao analisar uma obra de Willem Claesz Heda, da mesma série acima, Janson descreve:

O quadro pertence a um tipo muito corrente, mostrando
os restos de uma refeição. Os alimentos e a bebida têm
aqui menos importância que os objetos de luxo - taças
de cristal, pratos de prata - cuidadosamente justapostos
pelos seus contrastes de forma e textura. (...) Mas o
virtuosismo não foi o único objetivo do artista: a sua
'história', o contexto humano dos objetos agrupados, é-
nos sugerido pelo copo partido, pelo limão meio
descascado, a taça de prata tombada: quem se sentou a
esta mesa foi obrigado a abandoná-la de repente. Foi
como se o tempo tivesse baixado o pano sobre a cena,
investindo os objetos de um estranho poder emotivo, o
pathos das coisas. (Janson, 1977, 515-16)

A humanização dos objetos traduz-se também como tempo humanizado. É o que se pode perceber na utilização da caveira como um objeto frequente nas naturezas-mortas. Tomemos como exemplo a obra de Peter Claes, intitulada Vanitas.

Os objetos que a compõem têm separadamente um sentido, ou seja, cada um é símbolo de alguma coisa, pela ordem: a caveira (memento mori); o livro (sabedoria), a pena (maturidade), o relógio (passagem do tempo), a chave (abertura da percepção para a iluminação), o candeeiro apagado (extinção da vida), o copo tombado (extinção da vida) um cetro (poder, autoridade).

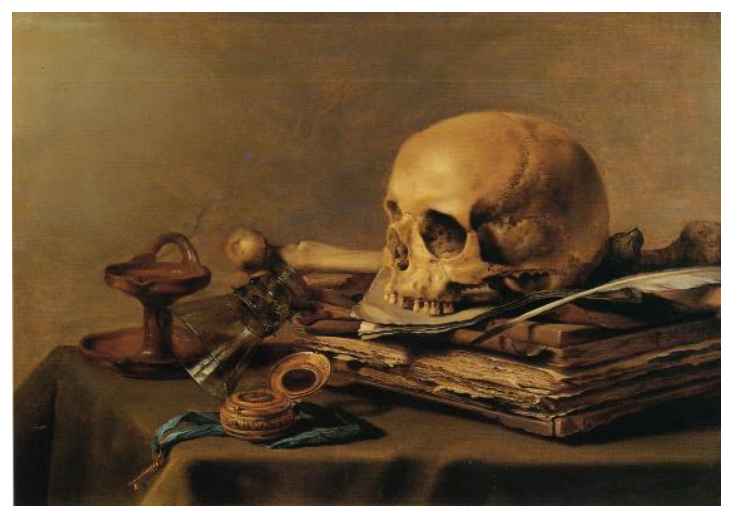

Figura 2: Peter Claesz - Vanitas - 1630. Oil on canvas, $39,5 \times 56 \mathrm{~cm}$. Mauritshuis, The Hague. Acesso em 12 de janeiro de 2015, from http://www.wga.hu/index1.html. 
Somados vão adquirir um significado maior: compõem a alegoria das Vaidades, não esquecendo que em latim, vanitas também significa "inutilidade". Para Benjamin,

a alegoria mostra ao observador a facies hippocrática da história como protopaisagem petrificada. A história em tudo o que nela desde o início é prematuro, sofrido e malogrado, se exprime num rosto - não, numa caveira. E porque não existe nela nenhuma liberdade simbólica de expressão, nenhuma harmonia clássica da forma, em suma, nada de humano, essa figura, de todas mais sujeita à natureza, exprime, não somente a existência humana em geral, mas de modo altamente expressivo, sob a forma de enigma, a história biográfica de um indivíduo (Benjamin, 1984: 189).

Já no século $X I X$, os pintores de naturezas mortas farão equivaler arte e ciência e, nesse exato momento, vem a público a fotografia, o que provocará a necessidade de reformulação da linguagem pictórica e redefinição de sua essência e objetivo frente ao novo instrumento de apreensão mecânica da realidade (Argan, 1993: 75). Encontramos naturezas-mortas em Monet, em Cézanne e Matisse, nos artistas cubistas, expressionistas, futuristas e surrealistas, mas a partir daqui, terá arrefecido seu caráter alegórico passando a primeiro plano a necessidade de mostrar-se como uma "forma" pictórica. Trata-se, todavia, de tema caro aos pintores porque lhes permitia a reflexão e pesquisa de formas e cores, bem como questionamentos do lugar da arte e do artista na sociedade moderna.

Em A partilha do sensível, Rancière afirma que a fotografia não se tornou arte por causa de sua natureza técnica. Também não se tornou arte por apropriar-se dos procedimentos e temas da pintura que lhe asseguraram o

estatuto da arte fotográfica, mas sim a assunção do qualquer um. (...) A revolução técnica vem depois da revolução estética. Mas a revolução estética é antes de tudo a glória do qualquer um - que é pictural e literária, antes de ser fotográfica e cinematográfica" (Rancière, 2005: 48).

Além dessa banalização e ampliação do campo, pensa-se agora sobre o caráter indicial da fotografia, ou a lógica do 
índice relacionada à imagem fotográfica, o que em princípio poderia afastar suas possibilidades alegóricas. Relembrando a lição peirceana, o índice é um atributo do signo que guarda uma ligação física com o objeto, diferentemente do ícone, onde há uma ligação de semelhança, e do símbolo que se relaciona ao objeto submetendo-o a uma lei ou convenção geral de significado.

O índice confere, então, ao signo singularidade, na medida em que é marca de determinado objeto e não de outro; atestação, na medida em que é evidência da existência de determinado objeto; e designação, na medida em que aponta e mostra o objeto do qual é marca (Apud Gil, 2012: 211).

No entanto não se pode perder de vista nem os fatores culturais envolvidos na produção da imagem nem o que Barthes (1984: 27-28) denominou a essência da fotografia, o "isso foi" (Barthes, 1984: 141). Ao mesmo tempo em que a fotografia é índice de algo que existe, é certo que já não mais existe daquela maneira. Se tomarmos como objeto de reflexão a fotografia The Open Door, realizada em 1838 por William Fox Talbot $^{1}$, podemos perceber que o fotógrafo exerceu a liberdade de escolher temas da vida cotidiana abertos pela pintura holandesa do século XVII, conforme comenta em seu livro The Pencil of Nature.

1 William Fox Talbot (1800-1877) inventor do calótipo (1841), processo de negativo em papel que permitia a reprodução de múltiplas imagens por fotógrafos profissionais e amadores. Oferecia uma resolução melhor do que a dada pelo daguerreótipo. 


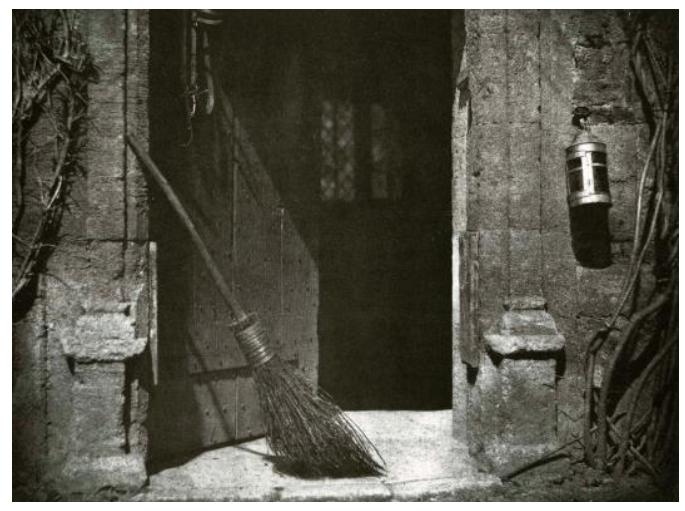

Figura 3: William Fox Talbot - The Open Door - 1838. Salted paper print from paper negative; $14.3 \times 19.4 \mathrm{~cm}$. Gilman Collection - Met museum of Art New York. Acesso em 12 de janeiro de 2015, from http://www.metmuseum.org/collection/the-collection-

online/search?ft=photographs+william+fox+talbot.

O olhar do pintor, segundo ele, consegue tornar notável aquilo que é simplesmente ordinário. Assim ele, Talbot, se concentra no antigo batente de pedra, na porta de madeira do estábulo e na vassoura, como também nos arreios e lanterna como objetos para um ensaio sobre a luz e a sombra, interior e exterior, forma e textura. No entanto, não é o caráter indicial da fotografia que irá garantir um significado pré-dado, e nem mesmo irá exercer um efeito determinado, mas sim o sistema discursivo de que faz parte. Como descreve John Tagg: "a natureza indicial da fotografia - o vínculo causal entre referencial pré-fotográfico e o signo - é enormemente complexo, irreversível, e não pode garantir nada no âmbito do significado (Tagg, 2005: 9)".

Desta forma, o distanciamento entre o objeto, seu sentido icônico e simbólico e a alegoria parece se aprofundar com o uso da fotografia, porque de fato tem início uma revolução estética provocada pelo seu aperfeiçoamento. A fotografia expõe também o que acontece com o sujeito que a enquadra e que Ihe dá materialidade. A ideia de modernidade aí implícita não pode ser ignorada. Neste sentido, em Natureza morta com Leica e caderno, o russo Aleksandr Rodtchenko põe em prática o pensamento construtivista que norteou sua produção envolta no slogan "Nosso dever é experimentar". Resumidamente, o 
método Rodtchenko implicava a composição em diagonal e o encurtamento. Diz o fotógrafo:

Para acostumar as pessoas a ver a partir de novos pontos de vista, é essencial tirar fotos de objetos familiares, cotidianos, a partir de perspectivas e de posições completamente inesperadas. Novos assuntos têm que ser fotografados de vários pontos, de modo a representar o assunto completamente (Rodtchenko, 2011: 60).

A escolha dos objetos, a caneta, o caderno e a fotografia remetem à natureza morta, reforçada pelo título.

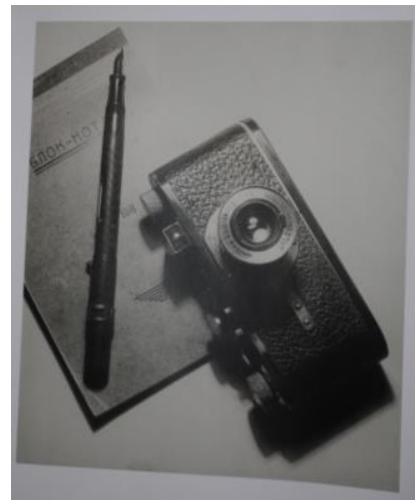

Figura 4: Aleksandr Rodchenko - Natureza-morta com Leica e caderno. 1930. Para capa da Revista Jurnalist - reprodução 30x43cm. Fonte: catálogo de exposição. Rio de Janeiro: Instituto Moreira Sales; São Paulo: Pinacoteca do estado, 2011: 104.

No entanto, para que o sentido alegórico seja atualizado é necessário ir além do indicial, uma vez que a apreciação da fotografia se dá entre esses dois campos. O embate está entre o referente, o gênero, e a significação. Se aproximarmos a Natureza morta do fotógrafo russo à Vanitas de Claesz, podemos compreender seu caráter alegórico. A máquina como substituta do olho humano, símbolo da percepção intelectual, aquele mesmo dado pela caveira, a pena substituída pela caneta e o livro pelo bloco de notas. Ou seja, uma atualização da alegoria do conhecimento como história de vida de um sujeito, agora mediada pela máquina. Todavia, todos os objetos estão singularizados pelo ângulo em que foram fotografados. 
Também Cartier-Bresson apresenta uma natureza morta, uma fotografia a qual dá o título do local em que foi tirada - Tívoli, na Itália, em 1933.

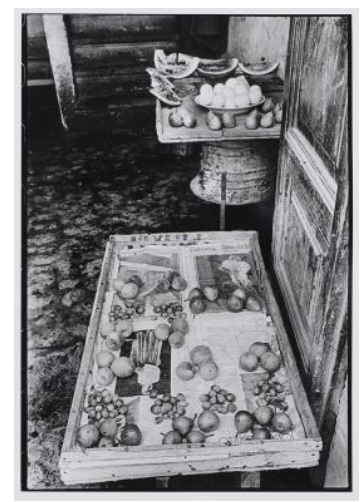

Figura 5: Henri Cartier-Bresson. Tívoli. 1933. Fotografia. Fonte: Henri Cartier-Bresson. Texto de Jean Clair. Trad. André Telles. São Paulo: Cosac Naify, 2011: 15.

Conhecendo sua visão acerca do ato de fotografar o instante, o "momento decisivo", é de se interrogar pelo sentido dessa fotografia. $O$ tabuleiro em primeiro plano com as frutas esparsas sobre folhas de jornais, fotografado de cima para baixo, enquadrando ainda a porta à direita constituindo um anteparo e uma diagonal, conduz a um outro tabuleiro equilibrado sobre um tambor cilíndrico, onde estão colocadas peras empilhadas, limões dentro de um recipiente e fatias de melancia ordenadas de modo a constituir uma moldura. Ao fundo, uma escada. O ângulo a partir do qual foi feita a tomada, ao invés de jogar com a profundidade da cena, pelo contrário, induz a um achatamento do espaço, remetendo às gravuras japonesas, às naturezas mortas de Cézanne e até mesmo, às pinturas de Morandi. É Cartier-Bresson quem afirma:

\footnotetext{
Para 'significar' o mundo, temos que nos sentir implicados no que recortamos através do visor. Essa atitude exige concentração, sensibilidade, senso de geometria. E por uma economia de meios e, sobretudo, um esquecimento de si mesmo que chegamos à simplicidade de expressão. (...) Fotografar é num mesmo instante e numa fração de segundo, reconhecer um fato e a organização rigorosa das formas percebidas visualmente que exprimem e significam esse fato (Cartier-Bresson, 2011:12).
} 
É nesta medida que podemos compreender o título que se encontra inscrito no primeiro tabuleiro, onde também é possível visualizar as imagens do jornal, páginas sobre cinema, com fotografia de atores. Ora, ao associar as frutas e as figuras humanas mediadas já pela fotografia e pelo jornal, CartierBresson remete à natureza-morta, a vanitas. Além disso, o achatamento também faz do segundo tabuleiro com frutas um quadro, uma pintura de natureza-morta.

Com uma polaroide de Robert Frank também podemos recuperar a ideia alegórica implicada na natureza-morta.

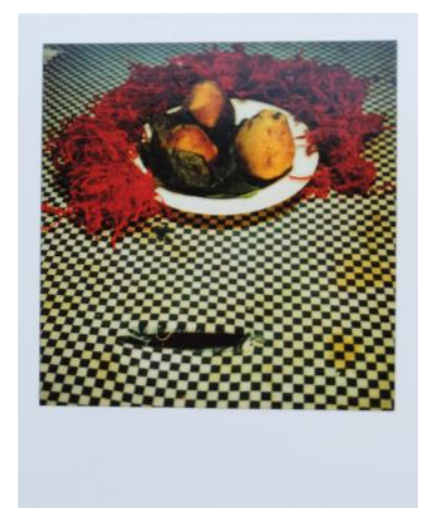

Figura 6: Robert Frank - Natureza-morta - polaroide, 9x11cm, publicada no livro Seven Stories, 2009. Fonte: Zum Revista de fotografia (1): p.22. Rio de Janeiro: Instituto Moreira Sales.

De acordo com Luc Sante, "A polaroide esvazia noções como a perfeição e a busca da obra-prima. São esboços. O meio impede a trapaça, encoraja a espontaneidade e recusa conclusões (2011: 26)". Não há como negar o arranjo das frutas no prato, com uma toalha vermelha envolvendo-os, criando uma restrição de campo sobre a toalha xadrez. Enquanto as frutas traduzem um certo frescor, uma vez que ainda estão envolvidas pelo papel de seda que as conserva para venda, a toalha é o elemento temporal mais evidente. As manchas amareladas reportam a uma duração que será interrompida pelo rasgo, um talho involuntariamente realizado, supõe-se. A polaroide "expressa a imperfeição material com delicadeza, às vezes com romantismo", afirma Sante (2011: 26). O ataque visual do xadrez é interrompido pelo rasgão ao 
mesmo tempo em que insere um traçado histórico no ambiente doméstico. As cores quentes e familiares das frutas e da toalha, também se impõem sobre a organização implícita no xadrez que ocupa a maioria do plano. Então a natureza-morta recupera aqui sua capacidade alegórica, combinando natureza e história.

O mesmo irá acontecer na fotografia de Francesca Woodmann: (2012), da série Providence.

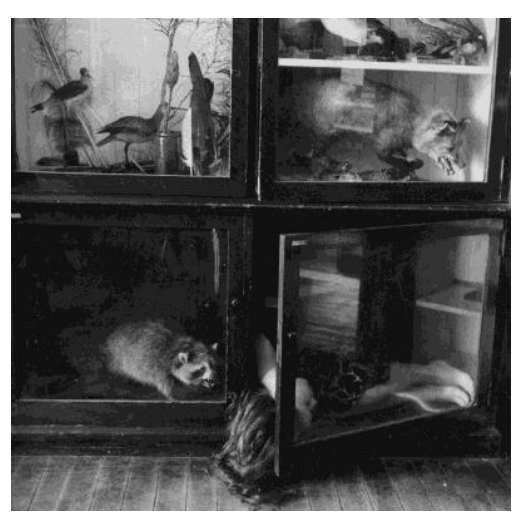

Figura 7: Francesca Woodmann. Série Providence, Rhode Island, 1975-78. Fonte: Zum Revista de fotografia (3), p. 29.

Um grande armário guarda bichos empalhados, em portas fechadas, mas na última porta, entreaberta, embaixo, à direita, vemos um corpo de mulher. Francesca Woodman introduz a ironia como um dado imprescindível ao seu trabalho, ao mesmo tempo em que se inclui nas fotografias, a exemplo de Cindy Scherman, dando legitimidade à encenação e à narrativa na arte fotográfica (Lubow, 2012: 39). É na fotografia de moda que vai buscar seu modelo, mas a encenação traduz, antes, os limites de interação com o espaço e com o tempo. Um animal empalhado conta sua história anterior, mas congela o momento em que foi morto. Sua vida é dada à contemplação até aquele instante e eternizada. Da mesma maneira a fotografia de moda capta o seu tempo distinto dos demais. Para Agamben, o "tempo da moda está constitutivamente adiantado a si mesmo e, exatamente por isso, também sempre atrasado, tem sempre a forma de um limiar inapreensível entre um 'ainda não' e um 'não mais' (Agamben, 2013: 67)'. Ao fotografar-se, Woodmann 
desconstrói-se como sujeito e no lugar de still life teremos então still frame, como em Cindy Sherman encontramos o still cinematográfico. Por outro lado, também se trata de uma alegoria nos domínios do memento mori. Se ainda não morri e estou eternizada pela fotografia, é evidente que esse momento chegará. Woodmann configura assim, o "isso-foi" barthesiano, a pequena história-narrativa de um sujeito que se suicidou aos 22 anos.

Diante desses exemplos de utilização da natureza-morta, podemos afirmar com Benjamin que não se pode negar a relação do alegórico com "o fragmentário, amontoado e desordenado de um quarto de um mágico ou de um laboratório de um alquimista, como o conheceu o Barroco (Benjamin, 1984: 210)". No entanto essa necessidade de conjugar o disperso vai provocar novas formas de ordenação.

Na poesia, quando Mallarmé propõe o poema como um lance de dados, está indicando que essa dispersão só poderá ser conjugada pelo leitor, levando em consideração um elemento que normalmente não seria visto como "poético", os caracteres tipográficos de tamanhos variados dispostos segundo uma nova lógica do sensível. É preciso levar em conta que no "regime estético da arte, a arte é arte na medida em que é algo além da arte. É sempre estetizada, o que quer dizer que é sempre colocada como uma forma de vida (Rancière, 2014: 6)".

Podemos, nesta perspectiva, pensar o poema fruteira, de Ana Martins Marques. Trata-se de um dos quadros a compor a parte do livro A Arte das Armadilhas (2011: 15), denominada "Interiores". Ao lado de poemas sobre objetos como açucareiro, cadeira, cristaleira, e relógio, entre outros, a fruteira se posiciona como uma natureza-morta. Composto pelo título e três versos, o poema remete a vanitas. De fato, os três versos são uma única frase interrogativa. Uma frase cujo aspecto condensa seus sentidos incoativo (inicial), cursivo (desenvolvimento) e conclusivo. 


\section{Fruteira}

Quem se lembrou de por sobre a mesa essas doces evidências da morte?

Ao utilizar o verbo lembrar-se no passado, o que denominamos aspecto perfectivo, a ação é apresentada na sua totalidade. No entanto, há que se pontuar a utilização também das expressões em contraste: "doces evidências" / "da morte", bem como dos objetos in absentia, as frutas, reduzidas ao espaço de derivação do título "fruteira", tratadas como "doces evidências da morte". É a isto que chamamos, a partir de Rancière (2014: 12), de criação do novo sensorium, um novo etos. Em outras palavras, apenas no poema vamos encontrar a realidade criada pelo poema, ainda que se constitua de elementos reconhecíveis do cotidiano. É aqui que o banal se torna belo como rastro do verdadeiro (Rancière, 2005: 50). É aqui que a alegoria retoma seu espaço constituindo-se em história e natureza ao mesmo tempo. Se quisermos ampliar a percepção alegórica, podemos juntar todos os outros poemas dedicados aos diversos objetos que fazem parte de "Interiores". Neles encontraremos as mesmas marcas do banal e do belo associadas, como em "Cômoda", onde podemos ler: "E dela/o que restou/ senão/sobre a cômoda/um par de brincos/que talvez não sejam dela? (Marques, 2011: 17)", num evidente poema cíclico e questionador de vida e de identidade.

A transformação dada pela linguagem poético-literária propõe ao leitor que busque em seu repertório as referências sobre os temas para poder apreendê-los na maior extensão possível. Conhecer a história da pintura e nela a história da naturezamorta como gênero possibilita a compreensão da passagem de sua condição indicial, para a icônica, a simbólica e, finalmente, a alegórica, quer se trate de pintura, de fotografia ou de poema. Por isso, talvez seja mais impactante o uso do tema em vídeoarte. Sam Taylor Wood, reconhecida por seus trabalhos em 
vídeo filmados em tempo real, recorre ao tema da natureza morta - Still life (2001), criando um vertiginoso memento mori.

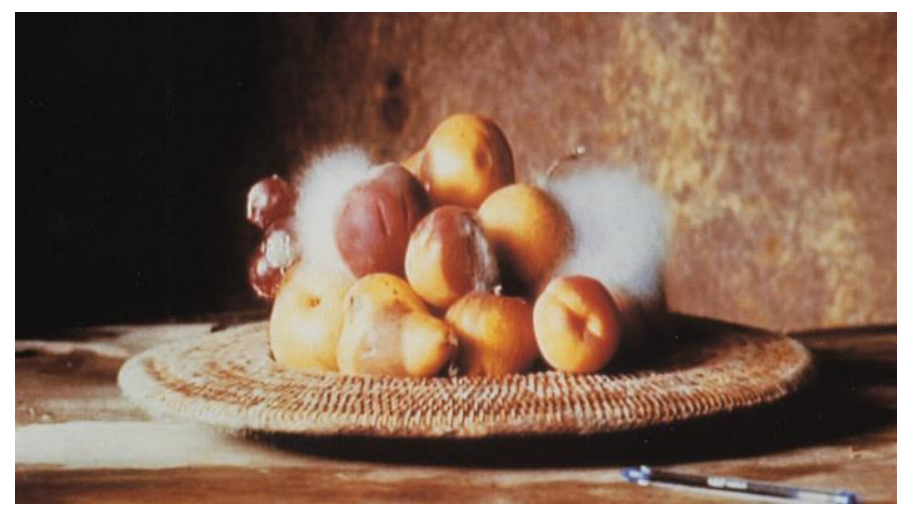

Figura 8: Sam Taylor-Wood. Still life. Video. Acessado em 12 de janeiro de 2015, from http://youtu.be/pXPP8eUIEtk.

As frutas, tomadas pelos fungos, vão apodrecendo rapidamente e se transformando num amontoado de bolor. A fruteira de fibra natural também é recoberta pelos fungos. A nota diferenciada é dada por uma caneta bic, displicentemente posicionada ao lado da fruteira. A presença desta caneta transforma o vídeo numa peça alegórica, trata-se novamente da expressão da vida cotidiana associada à sabedoria.

Ainda que não seja necessário, ou até mesmo desejável, concluir sobre a impossibilidade de se dissociar, dissolver ou ocultar o caráter alegórico vinculado ao tema das naturezas mortas, ele aponta necessariamente para a permanência da questão proposta por vanitas e pelo memento mori, porque se somam aos universais humanos. Por mais espetacular que nos possa parecer o mundo atual, ser contemporâneo requer que o possamos olhar sob outras luzes, talvez aquelas das sombras explicitadas por Agamben (2009: 64), conferindo um sentido mais profundo e, talvez por isso mesmo, mais humano, mais delicado, da nossa presença neste mundo. As naturezasmortas não nos deixam esquecer isso.

\section{Referências}


Agamben, G. (2009). O que é contemporâneo? e outros ensaios. Trad. Vinicius Nicastro Honesko. Chapecó, SC: Argos.

Argan, G. C. (1993). Arte Moderna. Trad. Denise Bottmann. São Paulo: Companhia das Letras.

Barthes, R. (1984). A câmara clara. Trad. Júlio Castañon Guimarães. Rio de Janeiro: Nova Fronteira.

Benjamin, W. (1984) A origem do drama barroco alemão. Trad. Sergio Paulo Rouanet. São Paulo: Brasiliense.

Cartier-Bresson, Henri. (2011). Henri Cartier-Bresson. Introd. Jean Clair. Trad. André Teles. São Paulo: Cosac Naify. (Photo Poche).

Gil, T. (2012) Fotografia e memória: um estudo sobre alguns trabalhos de Christian Boltansky e Rosângela Rennó. Boletim. Grupo de Estudos em Arte e Fotografia (4): 211-221.

Janson, H.W. (1979). História da arte. Trad. J. A. Ferreira de Almeida. Lisboa: Fundação Calouste Gulbenkian.

Lubow. A. (2012). A dança da solidão: Francesca Woodmann. Zum Revista de fotografia (3): 26-43. Rio de Janeiro: Instituto Moreira Sales.

Marques, A. M. (2011). A arte das armadilhas. São Paulo: Companhia das Letras.

Rancière, J. (2005). A partilha do sensível: estética e política. Trad. Mônica Costa Netto. São Paulo: EXO experimental org.; Ed. 34.

. (2014). A revolução estética e seus resultados. Projeto

Revoluções. Acesso em 15.10.2014, em http://www.revolucoes.org.br/v1/sites/default/files/a_revolucao_estetic a_jacques_ranciere.pdf

Rodtchenko, A. (2011). Revolução na fotografia. Catálogo de exposição. Rio de Janeiro: Instituto Moreira Sales; São Paulo: Pinacoteca do Estado.

Sante, L. (2011). Contra a imagem perfeita. Fotografias de Robert Frank. Zum Revista de fotografia (1): 22-27. Rio de Janeiro: Instituto Moreira Sales.

Tagg, J. (2005). El peso de la representación. Ensayos sobre fotografias e historias. Trad. Esp. Antonio Fernandes Lara. Barcelona: Gustavo Gili. 
Wood, Sam Taylor. (2001). Still life. Vídeo. Acessado em 12.02.2014, em: http://youtu.be/BJQYSPFo7hk 